\title{
mLLTTAS
}

33.3.2017 [302-321]

\section{MENGGALI DIMENSI POETIK AGAMA: SUMBANGAN KREATIF HEIDEGGER TERHADAP} AGAMA

\author{
Thomas Kristiatmo
}

\author{
| Faculty of Philosophy \\ Parahyangan Catholic University \\ Bandung, Indonesia
}

\begin{abstract}
:
Religion continues to exist despite the various attacks directed to its various elements. The secularisation thesis does not apply to the contemporary world, wherein religion proves itself to be an institution that always finds a place through the endless changes in human civilisation that has witnessed a growing number of violence in the name of particular religious values. Heidegger's ideas could serve as tools to unravel this pandemonium. His philosophy makes head or tail of the religion's features that have gone awry due to the lack of mystical elements. Heidegger proposes a fresh way of understanding religion through his reflection on the significance of dwelling poetically. Drawing inspiration from Hölderlin, he reflects upon the importance of poiesis, that is, an understanding on how human beings should live out religion so that it could always be relevant and enlightening.
\end{abstract}

Keywords:

religion • das Geviert • dwelling • revelation • mysticism 


\section{Pengantar}

Di tengah maraknya isu kekerasan atas nama agama, pemikiran Heidegger bisa menjadi tawaran yang perlu dipertimbangkan oleh agamaagama untuk berbenah diri. Begitu banyak keutamaan sejati dalam agama yang sering kali justru lenyap ditelan bumi, digilas oleh berlaksa hal tidak esensial dalam agama yang terus mencoba untuk tampil menjadi seolaholah yang utama. Celakanya, penggilasan macam itu banyak menuai keberhasilan. Di sana-sini agama tampil dalam wujud tidak ramah, hendak melenyapkan segala intensitas pergumulan anak manusia dengan semesta. Agama kini mesti berbenah, berbuat sesuatu agar, bersama dengan ilmu pengetahuan dan seni, sungguh-sungguh mampu menjadi penyokong peradaban manusia. Adalah ironis apabila agama yang mestinya cukup kuat membetot manusia masuk dalam samudra makna, malah membuat manusia semakin naif, picik, dan terlalu egoistis.

Sejak awal pemikiran Heidegger sudah terkait dengan isu-isu religius. ${ }^{1}$ Caputo mencatat bahwa keterlibatan Heidegger dalam bidang religius ini tidak lepas dari sejarah hidup Heidegger, yang terlahir di tengah suasana keagamaan kuat. Bahkan, ia sempat menempuh pendidikan sebagai seorang calon pastor Katolik. Tidak heran bila unsur religius ada dalam filsafatnya. Namun, ia, sebagai filsuf, tidak bicara dalam posisi sebagai wakil dari lembaga agama tertentu. Ia memutuskan untuk berpisah dari sistem Katolisisme. ${ }^{2}$ Jejak pemikiran religius lebih muncul dalam bentuk mistisisme yang kuat dalam filsafatnya. ${ }^{3}$ Mistisisme jauh lebih luas ketimbang sekat-sekat yang mungkin tercipta di antara agama-agama formal. Refleksi mistik-filosofis Heidegger bergema universal lantaran ia tidak mau jatuh dalam ajaran-ajaran agama tertentu.

\section{Menelisik Persoalan}

Abad ke-16 menjadi saksi bergesernya pola pikir teosentris ke antroposentris. Bila yang pertama amat menekankan otoritas Allah sejauh dirumuskan oleh agama institusional, yang kedua menekankan otonomi manusia. Otoritas Gereja Katolik di Eropa, yang sejak Edik Milano Kaisar Konstantinus Agung di abad ke-4 telah menjadi kokoh dan bahkan tetap bertahan manakala kekuatan politik penyokongnya telah runtuh, ternyata mengalami hantaman keras. Martin Luther mengawalinya. Cogito ergo sum dari Descartes dengan teguh menggarisbawahi segala tendensi 
yang meletakkan manusia, yaitu kesadarannya, sebagai acuan utama dalam berefleksi. Otoritas Allah yang secara institusional dijalankan oleh institusi agama perlahan mulai kehilangan taring. Dalam upaya sintesis atas rasionalisme dan empirisisme Kant, otoritas manusia sebagai subjek yang berpikir menjadi amat sangat kokoh. Kendati Kant menempatkan Allah sebagai satu dari ketiga postulatnya, otonomi tetap menduduki peran sentral dalam reflektivitas manusia.

Kini, empat abad lebih telah berlalu sejak hiruk-pikuk pergeseran dari teosentrisme ke antroposentrisme. Agama, lebih-lebih sejak munculnya gelombang sekularisasi, semakin tersingkir dari ruang publik. Kebangkitan agama di sana-sini memang terjadi, tapi tidak jarang justru melahirkan cibiran karena pertautannya dengan aksi-aksi teror maupun fundamentalisme yang membabi-buta. Telah demikian impotenkah agama sehingga ia layak disingkirkan dari berbagai sisi hidup bersama manusia? Mestikah ia dibebaskan dari institusi dan melulu menjadi ruang privat bagi tiap orang? Itu hanyalah dua dari banyak pertanyaan yang bisa muncul manakala orang berbicara tentang agama di saat kemanusiaan telah mantap dengan otonominya.

Uniknya, kendati mengalami gempuran dari berbagai sisi, agama tetap bertahan di tengah-tengah peradaban manusia. Walaupun Freud menuduh agama sebagai infantilisme dan gejala neurosis, Jung mencatat,

"Saya telah menangani ratusan pasien, sebagian besar di antaranya adalah Protestan, sebagian lagi Yahudi, dan tidak lebih dari lima atau enam Katolik. Di antara semua pasien saya dalam paruh kedua hidup saya... tidak ada satupun yang pada akhirnya persoalannya bukan mengenai menemukan cara pandang religius terhadap hidup. Adalah wajar untuk berkata bahwa setiap dari mereka jatuh sakit lantaran telah kehilangan apa yang diberikan oleh agama-agama di sepanjang zaman dan tidak seorangpun dari mereka yang telah benar-benar tersembuhkan yang tidak mendapatkan kembali cara pandang religiusnya." ${ }^{4}$

Bagi Jung, pandangan religius terhadap hidup membuat orang tetap sehat secara psikologis dan dengan begitu agama, dalam berbagai manifestasinya, tetap diperlukan oleh manusia.

Pada kenyataanya, agama tetap merasuk dalam setiap sendi kehidupan manusia. Manusia-manusia modern kini tengah mencari sebentuk kesatuan dan keutuhan diri, sebuah pengupayaan kembali perasaan, menentang keunggulan berat sebelah yang dipegang oleh nalar, 
dan pengupayaan kembali tubuh beserta kenikmatannya dari tempat inferior dan belumuran rasa salah dalam identitas yang terdisiplinkan dan instrumental. Ada tekanan pada unitas, integrasi, holisme, individualitas; bahasanya sering memacu harmoni, keseimbangan, kemengaliran, integrasi, menjadi satu, terpusat. ${ }^{5}$ Di tengah-tengah kemudahan yang didapat lewat artifisialitas, manusia mengalami kehausan untuk merasakan kenyamanan sejati dalam harmoni, keseimbangan dan integritas.

Contoh paling jelas dari upaya pencarian manusia ini adalah adanya kebangkitan mistisisme Timur dalam bentuk gerakan-gerakan New Age. Helena Blavatsky mendirikan Theosophical Society di paruh kedua abad ke-19 di Amerika Serikat. Awalnya, gerakan ini tidak menonjol. Seiring dengan gegap gempita revolusi kultural era 1960an di sana, mistisisme oriental semakin menyeruak masuk ke Amerika dan kemudian juga ke belahan dunia yang lazim disebut Barat. Sejak saat itu, Buddhisme, Shintoisme, Zen, Taoisme, Meditasi, dan Yoga menjadi praktik-praktik yang menjamur di kalangan orang Barat. Belakangan orang-orang di belahan Timur, yang ternyata sudah banyak mengalami ketercerabutan dari mistisisme kunonya, juga melirik New Age. Pada dasarnya, gerakan-gerakan tadi bersandar pada pantheisme, reinkarnasionisme, relativisme, dan esoterisisme. ${ }^{6}$

Manusia modern merasa enggan untuk berurusan dengan agama sebagai institusi. Mereka lebih senang menghargai bentuk-bentuk spiritualitas. Berkaitan dengan hal ini, penelitian Wade Clark Roof layak disimak. Salah satu orang yang diwawancarinya mengatakan bahwa agama lebih menyangkut perihal doktrin, tradisi, berlutut dan aturan-aturan lain; sementara itu, spiritualitas lebih masuk dalam wilayah batin yang nantinya justru akan membuat orang menjadi semakin baik, semakin terbuka. ${ }^{7}$

Manusia masih memiliki harapan dan keinginan untuk menemukan keutuhan diri lewat keterbukaan pada yang transenden. Berbagai bentuk spiritualisme yang menjamur sejak kemuncuan New Age menjadi bukti nyata. Orang masih mencari saat-saat fusi, yang membetotnya dari keseharian dan meletakkannya dalam kontak dengan sesuatu yang melampaui dirinya. ${ }^{8}$ Dengan sedikit mengingat pemikran Durkheim, saatsaat fusi macam itu sering didapat secara nyata dalam peristiwa-peristiwa kebersamaan yang khidmat: peziarahan ke tempat-tempat suci, saat ada perkabungan bersama akibat 9/11 atau akibat bencana tertentu, saat kaum Muslim menunaikan ibadah haji, dan lain sebagainya. Meskipun demikian, 
identitas yang sebetulnya bersifat spiritual belaka dan barangkali tidak berkaitan apapun dengan agama institusional itu pada titik tertentu juga tetap membutuhkan identitas yang mau tidak mau berupa institusi. Upaya privatisasi agama menjadi bentuk-bentuk spiritualisme, namun tidak bisa mengelak dari kebutuhan akan sosok nyata agama dalam organisasi, kaidah-kaidah normatif, dan ritus-ritusnya.

Agama kini tengah berada di zaman yang sering disebut dengan istilah payung 'postmodern'. Kendati muncul carut-marut peristilahan maupun hiruk-pikuk orang memperkarakan istilah itu, setidak-tidaknya ada tiga hal yang mengemuka dalam era yang disebut dengan istilah licin itu. Ketiganya adalah kemunculan persolan subjektivitas manusia, relativisme, dan keberlainan. ${ }^{9}$

Setelah menguat sejak munculnya zaman modern dan Aufklärung, subjektivitas manusia sempat nyaris lenyap seiring dengan datangnya arus pemikiran strukturalisme, psikoanalisis, dan para pemikir kontemporer seperti Foucault dan Derrida. ${ }^{10}$ Agaknya dominasi identitas subjek manusia yang dulunya dipegang oleh kesadaran dan ujung-ujungnya pada kemampuan rasionya tidak terbukti mampu membuat diri manusia utuh. Kekuatan reflektivitas yang melulu rasional, kendati mampu menghasilkan bermacam-macam temuan canggih, tidak dapat membuat manusia mencapai tahap kemanusiaan tertinggi. Berbagai skandal dalam sejarah menunjukkan: genosida, terorisme, kejahatan-kejahatan dunia maya, dan lain sebagainya. Sementara itu, subjektivitas manusia mesti diletakkan dalam kesatuan dengan yang transenden dan berdimensi lebih integral ketimbang sekadar kesadaran rasional.

Relativisme dan keberlainan semakin kentara menjadi isu penting lantaran dunia semakin kehilangan dimensi ruang dan waktunya. Berkat kemajuan sarana komunikasi, perbedaan ruang dan waktu tidak lagi menjadi persoalan. Simultanitas kini menjadi menjadi hal lumrah. Akibatnya, keragaman tata-nilai dan perbedaan yang ada di antara manusia, baik sebagai individu maupun kelompok, semakin jelas terlihat. Dalam konteks demikian, kebenaran yang diusung agama tidak lagi berupa objektivitas melainkan dialog interpersonal yang justru menjadi berefek bila diletakkan dalam nuansa berbagi bahasa. Berbagi bahasa tidak berarti berbagi objektivitas melainkan bersepakat atas sejumlah preferensi. Kesepakatan yang dicapai melalui preferensi ini dapat membangkitkan paradigma 
baru sebagai suatu "language game" baru yang mampu membebaskan penelitian dari penjara kosakata tunggal. ${ }^{11}$ Agama tidak lagi dapat dengan sewenang-wenang mengklaim diri sebagai agen tunggal pemilik kebenaran. Kebenaran bersifat perspektival. ${ }^{12}$ Agama yang ngotot menyebut diri sebagai satu-satunya pemegang kebenaran akan lenyap ditinggalkan pengikut.

Agama di era filsafat postmetafisik ini mestinya tidak lagi bergantung pada praktik-praktik ritual dan atribut-atribut luaran. Ia mesti mampu menyasar dimensi-dimensi terdalam relung hati manusia dan membawanya agar semakin menjadi manusia yang mengalami kebenaran, yaitu mendengar dan menafsir pesan-pesan. ${ }^{13}$ Dalam peri kehidupannya, entah ketika berbasah-basah dengan banalitas keseharian ataupun ketika menyelami kedalaman hidup, manusia mesti membuat interpretasi atas realitas yang tampil sebagai pesan-pesan baginya. Kebenaran paling ultim yang bisa dialami manusia adalah kebenaran cinta, kebenaran kasih. ${ }^{14}$

Dari penelusuran-penelusuran di atas tampak bahwa agama pada dasarnya masih diperlukan manusia. Tidak berlebihan bila Hans Küng menyebut bahwa perdamaian antarbangsa hanya bisa terwujud bila ada perdamaian antaragama. ${ }^{15}$ Bagaimanapun juga, agama adalah sumber energi dahsyat yang mampu membebaskan manusia menuju tingkat martabat kemanusiaannya yang tertinggi. ${ }^{16}$ Lepas dari kenyataan bahwa semakin banyak orang meninggalkan agama formal, agama tetap menawarkan makna yang bila digali dengan cermat akan memampukan manusia menjadi semakin manusiawi. Untuk menggiring agama ke arah sana, Heidegger memberi insights yang mencerahkan. Yang paling perlu dilakukan agama adalah menggali, menemukan lagi, dan mengembangkan dimensi poetiknya.

\section{...Secara Poetik Manusia Tinggal...}

Sebagai penggemar karya sastra, Heidegger menaruh perhatian besar pada Hölderlin. Dari salah satu puisinya Heidegger mendapat ilham untuk berefleksi tentang bagaimana manusia tinggal di atas bumi ini. Dalam artikel bertajuk “...Poetically Man Dwells..." judul itu didapat dari puisi Hölderlin. Pertanyaan yang kemudian mungkin muncul adalah bagaimana manusia dikatakan tinggal secara poetik? Jamaknya, orang memakai kata puitis, yang seakar dengan kata poetik, untuk menunjuk pada hal-hal yang bersifat atau berhubungan dengan 
puisi. Amat tidak lazim apabila kata tersebut dikaitkan dengan kata kerja 'tinggal'.

Heidegger mencoba menggali kata itu pada akarnya dalam bahasa Yunani, yaitu poiesis. Poiesis berasal dari kata kerja poiein yang berarti melakukan, membuat, memproduksi, menciptakan. Dalam arti yang kurang lebih demikian Heidegger menafsirkan kata-kata Hölderlin. Katanya,

"Keberadaan manusia pada dasarnya adalah poetik. Tapi kini kita memahami poetry sebagai sebuah pendasaran -lewat penamaan atas ilah-ilah dan esensi benda. 'Tinggal secara poetik berarti berdiri di hadapan kehadiran para ilah dan dihentak oleh kedekatan esensial benda-benda. Eksistensi itu pada dasarnya poetik - yang berarti serentak dibentuk dan sebuah karunia."'18

Lewat pernyataan itu Heidegger mengatakan bahwa pada dasarnya eksistensi manusia bersifat poetik. Di sini kelihatan bahwa dengan kata-kata itu, ia hendak menyebut dua hal yang paradoksal. Di satu sisi, eksistensi manusia adalah aktif lantaran dalam bereksistensi manusia melakukan "founding" dan "naming" tapi serentak juga eksistensi itu adalah sebuah karunia. Tinggal secara poetik berarti takzim di hadapan keilahian dan esensi segala macam hal yang ada dalam realitas. Tinggal adalah karakter dasar eksistensi manusia dan "poetry first causes dwelling to be dwelling ... and lets us dwell ... through building". ${ }^{19}$ Poetry dengan demikian terkait amat erat dengan eksistensi manusia yang berkarakter tinggal. Poetry memungkinkan manusia tinggal di muka bumi.

Secara sederhana bisa dikatakan sebagai berikut. Manusia bereksistensi di muka bumi ini. Dalam eksistensi itu, ia selalu tinggal. Tinggal di sini tidak sekadar menunjuk pada urusan perumahan. Tinggal di sini berarti manusia sungguh menjadikan bumi sebagai tempat ia merasa nyaman atau at home. Tidak setiap bangunan adalah tempat tinggal: jembatan, hanggar, stadion, dan pompa bensin adalah bangunan, tapi mereka bukan tempat tinggal. ${ }^{20}$ Untuk tinggal, manusia mesti membangun terlebih dahulu. Tujuan dari membangun adalah supaya manusia bisa tinggal. Di sini terlihat lebih jelas kata poetik yang dilekatkan pada tinggal. Poetik dalam hal ini menunjuk pada tindakan aktif manusia yang mengusahakan sesuatu untuk dirinya. Kutipan lebih lengkap bagian dari puisi Hölderlin itu adalah demikian:

Full of merit, yet poetically, man

Dwells on this earth 
Ada banyak hal yang diperoleh manusia lewat usahanya (merit) dan itu semua dimungkinkan karena manusia membangun. Heidegger melihat ada dua kata kerja dalam bahasa Latin yang cocok untuk menunjukkan aktivitas membangun yang dilakukan manusia: aedificare dan colere. Aedificare berarti mendirikan, membangun, memasang, menguatkan, membina, meneguhkan dan memberi teladan. Aedificare tidak sekadar menyangkut urusan fisik, tapi juga perkara mental dan disposisi batin. Sementara itu, colere berarti menanami, mengolah, memelihara, bercocok-tanam, merawat, mengerjakan sungguh-sungguh, menghormati, menyembah, berbakti dan merayakan. Pertautan antara kata membangun dengan kedua kata kerja tadi menjelaskan betapa dimensi paradoks yang sudah ada dalam kata sifat poetik yang menjelaskan tinggalnya manusia menjadi semakin paradoksal lantaran membangun sebagai sarana agar bisa tinggal juga mengandung paradoks. Paradoks ini tidak hendak membuat pembaca dan pendengar Heidegger bingung. Heidegger justru menunjukkan kekayaan dimensi eksistensi manusia di muka bumi.

Alih-alih menjauhkan manusia dari kehidupan nyata di muka bumi, dimensi poetik dalam tinggalnya manusia justru membuatnya semakin hidup secara konkret dan mampu berbuat sesuatu di muka bumi. Dalam kata-kata Heidegger, "Poetry tidaklah terbang mengawangawang untuk lari dari permukaan tanah. Ia justru yang membawa manusia menjejak bumi, membuatnya menjadi milik bumi, dan dengan demikian membuatnya tinggal." ${ }^{21}$ Lebih lanjut, Heidegger menerangkan kaitan antara membangun dan tinggal dengan melacak akar kata bahasa Jerman. ${ }^{22}$ Dalam bahasa Jerman, membangun adalah bauen. Bahasa Inggris kuno dan bahasa Jerman tinggi untuk kata membangun adalah buan. Uniknya, kata ini juga berarti tinggal. Dari kata itu pula diturunkan kata-kata untuk sein dalam bahasa Jerman: ich bin, du bist yang berarti saya tinggal, engkau tinggal. Sayangnya, penggunaan modern justru memisahkan apa yang terikat dengan kuat itu tadi. Mengingat dua kata kerja bahasa Latin yang tadi disebut, membangun juga menunjuk pada tindakan menyayangi dan melindungi, menjagai dan memedulikan, secara khusus mengolah tanah, bercocok tanam". ${ }^{23}$ Tidak hanya itu. Pelacakan lebih jauh pada akar kata modern untuk tinggal dalam bahasa Jerman, yaitu wohnen, menunjukkan lebih gamblang apa arti tinggal. ${ }^{24}$ Wobnen berasal dari kata Saxon Kuno wnon, yang dalam bahasa Gothik wnnian. Kedua kata kuno itu berarti 
tinggal dan pada kata dalam bahasa Gothik ternyata tidak hanya berhenti pada tataran tinggal tetapi juga terkandung pula bagaimana tinggal itu: ada dalam damai, dibawa dalam kedamaian, tinggal dalam damai. Dan dalam bahasa Jerman modern, perdamaian (der Friede) terkait dengan kata fry yang berarti menjaga dari bahaya. Pelacakan ini, sekali lagi, menunjukkan bahwa karakter fundamental dari tinggal adalah menjagai dan memelihara.

Semua penjelasan di atas menunjukkan, tinggal yang disokong oleh membangun tidak berkonotasi merusak. Dimensi poetik tidak melulu menunjuk pada upaya aktif mengusahakan untuk manusia saja. Rasa cinta pada yang didiami, pada jagad raya juga tersirat di balik kata-kata ini.

\section{Full of merit, yet poetically, man \\ Dwells on this earth}

Penjelasan-penjelasan di atas menunjuk pada manusia. Maksudnya, manusialah yang hendak diberi anjuran etis bagaimana semestinya ia tinggal di muka bumi. Meski demikian, ada satu hal yang amat menarik dari penyebutan Heidegger untuk manusia dalam hal ini: the mortals. Bila dalam periode Being and Time Heidegger sibuk dengan Dasein (manusia) dan dunia, di bawah pengaruh Hölderlin ia menggagas hal yang lebih universal. ${ }^{25}$ The mortals tidak pernah seorang diri, tapi selalu bersama dengan the mortals lainnya sekaligus dengan bumi, langit, dan keilahian. Inilah yang disebutnya sebagai das Geviert atau the fourfold. Keempat anggota di dalamnya saling sejajar dan berinterpenetrasi.

Bumi adalah penanggung yang melayani, yang bersemi dan berbuah, terhampar dalam bebatuan dan air, berkembang menjadi tanaman dan binatang. ${ }^{26}$ Agaknya di sini ditunjukkan adanya bumi sebagai "wadah" atau ranah tempat segala yang dilakukan oleh ketiga yang lain berlangsung. Ia ibarat panggung untuk pentas bagi ketiga yang lain.

Langit adalah jalan setapak Sang Surya, lajur pergerakan rembulan, pendar-pendar cahaya bintang-gemintang, musim-musim dalam tahun dan perubahannya, terang dan rembangnya hari, sendu dan baranya malam, murah hari dan bengisnya cuaca, awan-awan yang berlangkah, dan kedalaman eter. ${ }^{27}$ Langit menjadi penaung di atas, menjadi sesuatu yang memberi kesyahduan sekaligus menunjukkan kekejaman pada manusia. Pada tataran eksistensial, perubahan cuaca mulai dari yang cerah sampai pada saat badai topan menghardik manusia terjadi di langit. Dari situ muncul keteduhan sekaligus keberingasan alam. 
Keilahian adalah "the beckoning messengers of the godhead. Out of the holy sway of the godhead, the god appears in his presence or withdraws into his concealment". ${ }^{28}$ Di sini lalu bisa muncul interpretasi bermacam-macam. Heidegger memang tidak menyebut dengan eksplisit, apakah kemudian bisa menyamakan the godhead dengan Allah dalam kerangka agama Abrahamik, atau tidak. Kiranya untuk hal ini ia mendapat pengaruh dari mistisisme Meister Eckhart yang juga menyebut-nyebut perihal godhead. Meskipun demikian, yang hendak ditunjukkan adalah adanya Sang Ilahi yang memberikan pengaruh kuat pada ketiga bagian das Geviert yang lain. "The godhead seems to be the first by its holy sway. Its beckoning messengers are the divinities, and the god who appears and withdraws, appears only out of the holy sway of the godhead". ${ }^{29}$

The mortals adalah manusia. Manusia disebut sebagai the mortals karena mereka dapat mati, yaitu mampu menerima kematian sebagai kematian. ${ }^{30}$ Untuk menegaskan kesatuan di antara keempatnya, Heidegger mengulang refren yang sama setiap kali habis menjelaskan satu dari keempatnya: bilamana kita berbicara tentang ... kita sudah sedang berpikir tentang ketiga yang lain, tapi kita tidak memerhatikan kesatuan sederhana dari keempatnya. ${ }^{31}$

Kesatuan di antara keempatnya ini menunjukkan kuatnya dimensi kosmik pada pemikiran Heidegger. Singkatnya, ia mengagas sebuah upaya agar manusia menjadi sungguh-sungguh otentik, menjadi dirinya sendiri sebagaimana seharusnya. Otentisitas manusia yang sedang mengada ditentukan tidak hanya berkaitan dengan relasi antropologis semata-mata, melainkan juga dengan relasi kosmik.

Tilikan praktis dari das Geviert dijelaskan pula oleh Heidegger. Pertama, dikatakan bahwa the mortals tinggal lantaran mereka menyelamatkan bumi. ${ }^{32}$ Kata menyelamatkan di sini tidak saja berarti mengamankan dari segala bahaya yang mungkin mengancam. Menyelamatkan berarti pula membebaskannya untuk hadir (presencing). Kedua, the mortals tinggal dalam menerima langit sebagai langit. ${ }^{33}$ Artinya, manusia (semestinya) menerima perubahan alam yang diakibatkan oleh perubahan di langit: cuaca, siang-malam, perubahan tingkah polah jagad di atas. Ketiga, the mortals tinggal dalam penantian keilahian sebagai keilahian. ${ }^{34}$ Sebagai yang bersiap menerima sang pembawa pesan, manusia menantikan pesanpesan ilahi yang akan dibawakan oleh segenap hal yang dialaminya dalam 
pergulatan dalam das Geviert. Apapun yang terkandung dalam dirinya dan dalam ketiga unsur das Geviert mungkin saja menjadi pembawa pesan ilahi. Maka, manusia dituntut untuk terbuka. Keempat, the mortals tinggal dalam berinisiatif atas alamnya, yaitu menggunakan segenap kemampuan untuk nantinya menerima kematian sebagai kematian sedemikian sehingga manusia mengalami kematian yang baik. ${ }^{35}$ Dengan menjalankan keempat hal itu, tinggalnya manusia secara poetik akan berarti upaya untuk menjagai harmoni dalam das Geviert. Di sini kembali didapati pemikiran kosmik.

Pemikiran Heidegger kemudian juga akan mengarahkan manusia menjadi insan yang mendengarkan. Dunia manusia telah sedemikian teracuni oleh konsep berbicara, lebih daripada mendengarkan. Ini hal yang lumrah. Tatanan kultur manusia telah sedemikian dirasuki oleh konsep logos yang tidak menunjuk pada hal-ikhwal mendengarkan. Tapi, itu belumlah akhir dari segalanya. Pelacakan makna kata legein, di samping segala konotasinya yang berkaitan dengan urusan berbicara, membawa pula makna 'mengumpulkan', 'menjagai', 'menerima'. ${ }^{36}$ Makna kata logos, dengan demikian, mestinya dipahami dalam konteks kata kerja legein. Bagi Heidegger,

Who would want to deny that in the language of the Greeks from early on legein means to talk, say or tell? However, just as early and even more originally -and therefore already in the previously cited meaning- it means what our similarly sounding legen means: to lay down and lay before. In legen the bringing together' prevails, the Latin legere understood as lesen, in the sense of collecting and bringing together. Legein properly means the laying-down and laying-before which gathers itself and others. ${ }^{37}$

Pelacakan demikian menegaskan betapa dalam etimologi kata logos, yang demikian diagungkan manusia modern, telah terkandung makna mendengarkan. Celakanya, atas dasar pemahaman yang tidak lengkap terhadap kata logos itulah manusia membangun kulturnya. Hasilnya ialah kultur yang logosentris - dalam makna logos yang nirlengkap, tentu saja - dan monolitik. Pemikir besar yang hendak membongkar ini adalah Nietzsche. Ia menggagas sebuah cara berpikir yang sesuai untuk mendengarkan dan baru kemudian didengarkan dengan cara demikian sebuah fenomena bisa lebih terpahami secara lebih baik. ${ }^{38}$

Mestinya hal macam ini sudah bisa terdeteksi dalam proses belajar bahasa yang dialami setiap anak manusia. Saat hendak belajar berbicara dalam bahasa ibu, seorang anak akan mulai dengan mendengaran segala 
bebunyian dari mulut orang di sekitarnya. Bahkan, sebelum proses itu terjadi, seorang anak sudah terlebih dahulu memahami gesture maupun suara orang di dekatnya. Jauh sebelum masuk pada fase ketika anak bisa mengekspresikan diri dan merespon rangsangan dari luar secara verbal, seorang anak sudah mampu menangkap diskursus yang terjadi di sekitarnya. Proses mendengarkan telah terjadi. Setelahnya, baru anak belajar untuk berucap kata yang dilengkapi dengan seperangkat tata-bahasa. Sembari menggamit pemahaman-pemahaman di atas, berbicara pun pada akhirnya adalah sebuah tindakan mendengarkan. Manakala sesorang berbicara, ia mendengarkan apa yang sedang diperkatakan. Menurut Heidegger, "Speaking is of itself a listening. Speaking is listening to the language which we speak". 39

Dalam mendengarkan, manusia tetap bukanlah segala-galanya. Selalu ada yang menyelinap keluar dari apa yang dapat ditangkap oleh manusia lewat apa yang mampu ia dengarkan. Itulah yang disebut misteri. ${ }^{40}$ Dalam berhadapan dengan itu manusia mesti takzim, sembari meyakini bahwa Sang Misteri itu dalam berbagai manifestasi juga akan menguak dirinya.

Heidegger meyakini bahwa ketersingkapan Sang Misteri terjadi dalam bahasa karena "the logos lets lie before us what lies before us as such, it discloses what is presence in its presencing. But disclosure is aletheia". ${ }^{41}$ Manakala dipahami secara utuh, logos akan membawa manusia pada kebenaran yang berupa ketersingkapan itu sendiri. Bagi Heidegger, kebenaran ialah aletheia. Kata ini berasal dari bahasa Yunani yang secara etimologis berarti "yang tidak tersembunyi" 42 Dari situ ada tiga implikasi yang muncul..$^{43}$ Pertama, kebenaran tidak hanya terbatas pada pernyataanpernyataan eksplisit maupun putusan, keyakinan dan representasi. Kedua, kebenaran adalah pertama-tama sebuah fitur dari realitas. Ketiga, kebenaran menyiratkan atau bahkan mengandaikan adanya ketersembunyian. Dari situ bisa dilihat bahwa kebenaran tidak pernah menjadi sesuatu yang sekali jadi, yang sekali ditemukan lalu bisa dipegang seterusnya. Kebenaran itu dinamis dan akan terus tertemukan dalam dinamika, bukan dalam kemandekan. Alih-alih substansi, kebenaran lebih tepat bila dipahami sebagai peristiwa.

Mendengarkan, dalam pemikiran Heidegger, tidak berarti ajakan untuk melulu mendengarkan tanpa ada kesempatan untuk berbicara. Di atas 
sudah dilihat bahwa keduanya berasa dari sumber yang sama. Kemampuan untuk mendengar dan kemampuan untuk berkata-kata bersifat co-originary dan lantaran itulah sebuah percakapan bisa terjadi. ${ }^{44}$ Percakapan tentu mesti dimaknai secara mendalam. Ia tidak sekadar pembicaraan antara dua atau lebih orang. Percakapan adalah kesalingterhubungan antara komponenkomponen dalam das Geviert. Setiap saat masing-masing komponen sedang saling mendengaran dan berkata-kata: percakapan abadi tanpa henti.

Yang tidak kalah penting, bahkan menjadi syarat agar mampu mendengarkan, adalah keheningan. Heidegger menegaskan,

"In talking with one another, the person who keeps silent can 'make one understand' (that is, he can develop an understanding), and he can do so more authentically than the person who is never short of words. Speaking at length [Viel-sprechen] about something does not offer the slightest guarantee that thereby understanding is advanced. On the contrary, talking extensively about something, covers it up and brings what is understood to a sham clarity -the unintelligibility of the trivial. But to keep silent does not mean to be dumb. On the contrary, if a man is dumb, he still has a tendency to 'speak'. Such a person has not proved that he can keep silence; indeed, he entirely lacks the possibility of proving anything of the sort. And the person who is accustomed by Nature to speak little is no better able to show that he is keeping silent or that he is the sort of person who can do so. He who never says anything cannot keep silent at any given moment. Keeping silence authentically is possible only in genuine discoursing. To be able to keep silent, Dasein must have something to say -that is, it must have at its disposal an authentic and rich disclosedness of itself. In that case one's reticence [Verschwiegenheit] makes something manifest and does away with idle talk [Gerede]. As a mode of discoursing reticence articulates the intelligibility of Dasein in so primordial a manner that it gives rise to a potentiality-for-hearing which is genuine and to a Being-with-oneanother which is transparent. ${ }^{45}$

Sering terbukti bahwa sungguh-sungguh diam, atau berada dalam keheningan, justru akan memampukan orang untuk lebih memahami sesuatu dengan baik. Keheningan yang memungkinkan pemahaman tidak sekadar menahan mulut agar tidak berkata-kata. Keheningan adalah sebuah disposisi batin, yaitu batin yang tenang dan mampu terbuka pada suara ilham yang datang kepadanya. Keheningan, di masa teknologi canggih ini, telah demikian tergeser dari hidup manusia. Dari pagi hari, saat mulai membuka mata, sampai pada malam hari sebelum menutup mata, manusia terus-menerus mendengar berbagai-bagai kebisingan: suara radio, 
musik dari beragam piranti canggih, beragam percakapan dalam berbagai tingkat kualitas, dan lain sebagainya. Keheningan menjadi sesuatu yang menakutkan lantaran di dalamnya autentisitas dan kebenaran tertemukan. Manusia yang larut dalam kerumunan tidak berani berhadapan dengan peristiwa kebenaran yang terkuak. Padahal, keheningan ini mesti ada dalam tinggalnya manusia. Atau, keduanya mestinya menyatu dan terus menerus menjadi cara berada manusia. Ini bukan hal yang mustahil. Di tengah ketertenggelamannya dalam hal remeh-temeh, manusia tetap bisa mencipta keheningan. Berbagai bebunyian, kegaduhan, dan kebisingan tidak harus menjadi alasan untuk tidak berada dalam keheningan.

Heidegger sendiri memilih untuk hidup berkanjang dalam keheningan alih-alih tinggal di kota besar. Dalam penegasannya akan kecintaan terhadap Todtnauberg ia menuliskan,

"Orang-orang di kota sering heran, apa yang diperoleh orang dengan kesepian di gunung-gunung, di tengah-tengah para petani untuk waktu yang lama dan monoton. Tetapi itu bukan kesepian, itu adalah keheningan. Di kota-kota besar orang dapat dengan mudah merasa kesepian, namun orang tidak merasa hening di sana. Keheningan memiliki kekuatan yang khas dan asli tidak dengan mengisolasi kita, namun dengan memproyeksikan seluruh eksistensi kita dalam kedekatan dengan hakikat (Wesen) segala sesuatu." 46

Kendati untuk hening tidak selalu mensyaratkan ketiadaan hiruk-pikuk dan bebunyian, selama hidupnya Heidegger memilih untuk berteman dengan keheningan dengan menjauhi kebisingan. Dalam kutipan pendek tadi, dengan jelas pula ia membedakan kesepian dari keheningan. Dalam sebuah pesta, bisa saja seseorang merasa kesepian lantaran tidak seorangpun yang mendekati dan mengajaknya berbicara. Atau, seorang yang tinggal di sebuah apartemen dengan kesibukan karier luar biasa, bisa saja tibatiba tersentak saat menyadari bahwa segenap relasi yang ia bangun dengan rekan-rekannya serta ketertenggelamannya dalam berbagai kegaduhan hidup hanyalah terjadi pada tataran dangkal saja dan di dalam lubuk hatinya ia merasa tidak mendapat sentuhan hangat dari siapapun dan apapun.

\section{Dimensi Poetik Agama}

Sebagai seorang filsuf yang pernah menyatakan diri lepas dari sistem Katolisisme, Heidegger lebih tampil sebagai seorang mistikus. Pemikiran yang terpapar singkat di atas menunjukkan dimensi itu. Secara singkat bisa 
dikatakan bahwa ia mengemukakan refleksi mendalam tentang cara berada manusia di muka bumi. Refleksiitu kemudian tidak sekadar bercorak filosofis tetapi juga berdimensi mistik. Pemikiran tentang manusia kemudian juga mengarah pada kosmos dan sebuah integrasi harmonis antara manusia dan jagad raya. Dalam hal itu, Heidegger memberi kontribusi besar pada agama. Bahkan, ia "berteologi." Menurut Heidegger, "Someone who has experienced theology in his own roots, both the theology of the Christian faith and that of philosophy, would today remain silent about god when he is speaking in the realm of thinking". ${ }^{47}$ Pada dasarnya Heidegger tidak hendak berteologi, sebab ia tidak ingin terjerembab dalam ontoteologi. Ia lebih menempatkan teologi sebagai peristiwa yang dialami, bukan sebagai substansi.

Dari pemikirannya yang demikian, ia memberi kontribusi untuk agama. Agama mestinya mendorong orang untuk bisa tinggal, dan mampu mendengarkan, sebagaimana digambarkan oleh Heidegger. Agama yang saat ini ada seharusnya memampukan orang untuk berabstraksi dan bertindak secara jernih dengan memperhitungkan kesatuan dirinya dengan seluruh umat manusia, dengan seluruh kosmos.

Dalam diri manusia ada sebuah damba. "The care for seeing is essential to man's Being", ${ }^{48}$ kata Heidegger. Dari situ Heidegger berefleksi tentang kuriositas manusia untuk membuat segalanya menjadi hadir. Kuriositas tidak mengijinkan manusia berhadapan dengan absentia. Manusia mendamba untuk bisa memandang Yang Kudus, visio beatifica Dei. Yang seperti ini kemudian membuat teologi menjadi ontoteologi. Dalam ranah filsafat, keinginan manusia akan kehadiran ini menjelma menjadi "metafisika kehadiran" atau "ontologi substansi" yang secara umum menunjuk pada upaya-upaya penegasan bahwa pada titik ultim, apa yang real adalah sesuatu yang mendasari segenap hal, yaitu substansi. ${ }^{49}$

Di dalam metafisika kehadiran atau ontologi substansi, agama sering terjebak. Mestinya damba itu bukan dikaitkan dengan objek yang terumus dengan jelas, tetapi dianggap sebagai sebuah upaya untuk terus menerus berusaha tuned in dengan apa yang akan datang, yaitu Yang Kudus sendiri. ${ }^{50}$ Konsep wahyu dalam agama sebenarnya mendukung hal ini. Wahyu, terutama dalam Kristianitas, menunjuk pada komunikasi pribadi antara Allah yang transenden dengan manusia yang di bumi. ${ }^{51}$ Lewat komunikasi itu Allah mengundang manusia hidup dalam persekutuan dengan diriNya sendiri. Dalam hal itu, ada empat aspek yang menonjol: misteri ilahi, 
peristiwa sejarah, pengetahuan, dan perjumpaan pribadi. ${ }^{52}$ Dengan adanya keempat aspek tersebut, komunikasi diri Allah mesti ditanggapi manusia secara dinamis dan tidak ada satu institusi agamapun yang bisa mengklaim kebenaran yang beku membatu tanpa adanya keterbukaan pada apa yang mungkin bisa menjadi suara Sang Ilahi dalam segenap peristiwa yang ada di jagad raya.

Dalam tinggal secara poetik, manusia menantikan pesan-pesan Yang Kudus. Dimensi macam ini sebetulnya sudah ada dalam agamaagama besar. Para nabi adalah mereka yang mampu menangkap pesan dari Yang Kudus dan kemudian menyampaikannya kepada umat manusia. Para mistikus, yang tidak jarang alih-alih didengarkan malah dibantai, sebenarnya juga menunjukkan kesatuan antara manusia, keilahian, langit, dan bumi.

Pada abad ke-9, di tanah Iran Utara lahirlah al-Hallaj ke muka bumi. Ketika dewasa ia banyak berkotbah di Baghdad. Di situ pulalah ia berhadapan dengan Ibnu al-Furat dan Hamid. Al-Hallaj berkotbah tentang kesatuan jiwa dengan Allah. Ujung-ujungnya, ia disesah di hadapan banyak orang. Ia tidak langsung dipenggal: dibiarkan dalam keadaan setengah mati terlebih dahulu sampai hari berikutnya. Sebuah versi tentang kematiannya menyebut bahwa ia dihukum mati lantaran mengaku diri Allah, yaitu sebagai insan yang memiliki kesatuan sempurna dengan Sang Khalik sedemikan sehingga menjadi identik dengan Dia. ${ }^{53}$ Tampaknya kesatuan dengan Sang Khalik yang dialami al-Hallaj tidak dipahami oleh orangorang di sekitarnya. Bagi mereka, amat takabur dan berdosa beratlah orang yang sampai berani menyamakan diri dengan Allah. Padahal, kesatuan itu bukan hal yang mustahil diraih.

Mistikus adalah mereka yang telah mampu tinggal secara poetik di bumi. Mereka terus mengupayakan yang baik sembari tetap menjaga harmoni dengan semesta. Lebih lanjut, konsep silih menunjukkan bahwa agama tidak menghendaki ada disharmoni dalam semesta. Apa yang tidak harmonis mesti didamaikan kembali sehingga tercipta harmoni. Sebuah pengkhianatan atas harmoni mesti ditebus. Kesatuan das Geviert seperti yang digagas Heidegger searah dengan harmoni yang dicita-citakan agama.

Wahyu, mistikus, dan silih hanyalah sebagian kecil dari banyak hal lain lagi yang ada dalam agama dan memungkinkan manusia tinggal secara poetik sebagaimana diusulkan Heidegger. Sayangnya, agama lebih sering 
tampil sebagai hakim moral yang mutlak memutuskan segalanya, atau sebagai institusi raksasa yang hendak mengatur setiap sendi kehidupan manusia. Gagasan Heidegger yang sebetulnya sudah membawa benihbenih maupun faktor pendorongnya dalam agama-agama dapat membuka mata kita bahwa adalah tugas agama-agama untuk kini menggali, menemukan, serta mengembangkan percik-percik poetik yang ada dalam diri mereka. Tanpa upaya itu, kekerasan demi kekerasan atas nama agama akan terus terjadi.

\section{References:}

Caputo, John D. The Mystical Element in Heidegger's Thought. New York: Fordham University Press, 1986.

Dister, Nico Syukur. (2004). Teologi Sistematika. Yogyakarta: Kanisius.

Eliade, Mircea (ed. in chief). The Encyclopedia of Religion Vol. 6. New York: Macmillan Publishing Company, 1987.

Fiumara, Gemma Corradi. The Other Side of Language. London: Routledge, 1990.

Guignon, Charles B. The Cambridge Companion to Heidegger. Cambridge: Cambridge University Press, 1993.

Hardiman, F. Budi. Heidegger dan Mistik Keseharian. Jakarta: Kepustakaan Populer Gramedia, 2003.

Heidegger, Martin. Being and Time. trans. John Macquarrie \& Edward Robinson. Oxford: Basil Blackwell, 1980.

Early Greek Thinking. New York: Harper and Row Publishers Inc., 1984.

Elucidations of Hölderlin's Poetry. transl. Keith Hoeller. New York: Humanity Books, 2000.

Identity and Difference, transl. Joan Stambaugh. New York:

Harper \& Row Publishers, 1969. 1971.

On the Way to Language. New York: Harper \& Row Publishers,

Poetry, Language, Thought. transl. Albert Hofstadter. New York: Harper \& Row, 1975.

Inwood, Michael. A Heidegger Dictionary. Oxford: Blackwell Publishers Ltd., 1999. 
Jung, C.G. Modern Man in Search of a Soul. New York: Harcourt, Brace and Company, 1933.

Kristiatmo, Thomas. Redefinisi Subjek dalam Kebudayaan. Bandung: Jalasutra, 2007.

Küng, Hans. "Towards a World Ethic of World Religions." The Ethic of World Religions and Human Rights, Concilium 1990/2 (London: SCM Press, 1990).

Lakeland, Paul. Postmodernity. Minneapolis: Fortress Press, 1997.

Lewis, B et al. (eds.). The Encyclopadia of Islam vol. III. London: Luzac \& Co., 1979.

Paulus VI, Paus. Dei Verbum. 1965.

Rorty, Richard \& Giani Vattimo. The Future of Religion. New York: Columbia University Press, 2005.

Regan, H.D. et al. Christ and Context. Edinburgh: T\&T Clark, 1993.

Sugiharto, Bambang \& Agus Rachmat W. Wajah Baru Etika dan Agama. Yogyakarta: Kanisius, 2000.

Smith, David L. A Handbook of Contemporary Theology. Illinois: Victor Books, 1992.

Taylor, Charles. A Secular Age. Cambridge, Massachusetts, London: The Belknap Press of Harvard University Press, 2007.

Vedder, Ben. Heidegger's Philosophy of Religion. Pennsylvania: Duquesne University Press, 2006.

\section{Endnotes:}

1 John D. Caputo, "Heidegger and Theology" dalam Charles B. Guignon, The Cambridge Companion to Heidegger (Cambridge: Cambridge University Press, 1993) 270.

2 Penelusuran yang dibuat oleh Thomas Sheehan menunjukkan bahwa berpisahnya Heidegger dari sistem Katolisisme terkait erat dengan keadaannya sebagai seorang filsuf, yang berpikiran bebas dan tidak terikat pada sistem tertentu, berhadapan dengan Gereja Katolik yang pada waktu itu menjadi insitusi yang baginya kaku dan terlalu mengatur. Bdk. Thomas Sheehan, "Reading a Life: Heidegger and hard times" dalam dalam Charles B. Guignon, The Cambridge Companion to Heidegger (Cambridge: Cambridge University Press, 1993) 70-96.

3 Lih. John D. Caputo, The Mystical Element in Heidegger's Thought (New York: Fordham University Press, 1986) dan F. Budi Hardiman, Heidegger dan Mistik. Keseharian (Jakarta: Kepustakaan Populer Gramedia, 2003). 
4 C.G Jung, Modern Man in Search of a Soul New York: Harcourt, Brace and Company, 1933) 264.

5 Charles Taylor, A Secular Age (Cambridge, Massachusetts, London: The Belknap Press of Harvard University Press, 2007) 507.

6 David L Smith, A Handbook of Contemporary Theology (Illinois: Victor Books, 1992) 273-292.

7 Bdk. Wade Clark Roof, Spiritual Marketplace (Princeton: Princeton University Press, 1999) 137, dikutip dari Charles Taylor, A Secular Age, op. cit., 508.

8 Charles Taylor, A Secular Age, ibid., 516-517.

9 Bdk. Paul Lakeland, Postmodernity (Minneapolis: Fortress Press, 1997). Ada banyak versi tentang karakteristik postmodern. Dalam tulisan ini, ketiga hal tadi hanya dipakai sebagai konteks yang kiranya langsung bersentuhan dengan persoalan agama.

10 Bdk. Thomas Kristiatmo, Redefinisi Subjek dalam Kebudayaan (Bandung: Jalasutra, 2007).

11 Santiago Zabala, "A Religion without Theists or Atheists" dalam Richard Rorty and Giani Vattimo, The Future of Religion (New York: Columbia University Press, 2005) 8.

12 Bdk. Janet Martin Soskice, "The Truth Looks Different from Here" dalam H. D. Regan et al., Christ and Context (Edinburgh: T\&T Clark, 1993) 43-59.

13 Gianni Vattimo, "The Age of Interpretation" dalam Richard Rorty and Giani Vattimo, The Future of Religion (New York: Columbia University Press, 2005) 53.

14 Ibid., 51

15 Hans Küng, "Towards a World Ethic of World Religions" dalam The Ethic of World Religions and Human Rights, Concilium 1990/2 (London: SCM Press, 1990) 115.

16 Bambang Sugiharto, "Agama Sebagai Energi Pembebasan" dalam Bambang Sugiharto \& Agus Rachmat W., Wajah Baru Etika dan Agama (Yogyakarta: Kanisius, 2000) 262.

17 Martin Heidegger, “...Poetically Man Dwells...” dalam Martin Heidegger, Poetry, Language, Thought, transl. Albert Hofstadter (New York: Harper \& Row, 1975) 213 229.

18 Martin Heidegger, Elucidations of Hölderlin's Poetry, transl. Keith Hoeller, (New York: Humanity Books, 2000) 60.

19 Martin Heidegger, “...Poetically Man Dwells...”, art. cit., 215

20 Martin Heidegger, "Building Dwelling Thinking” dalam Martin Heidegger, Poetry, Language, Thought, transl. Albert Hofstadter (New York: Harper \& Row, 1975) 145.

21 Martin Heidegger, "...Poetically Man Dwells...", art. cit., 218.

22 Bdk. Martin Heidegger, "Building Dwelling Thinking", art. cit., 146-147.

23 Ibid., 147.

24 Bdk. ibid. 148-149.

25 Bdk. Michael Inwood, A Heidegger Dictionary (Oxford: Blackwell Publishers Ltd., 1999) 50.

26 Martin Heidegger, "Building Dwelling Thinking", art. cit., 149.

27 Ibid. 
28 Ibid., 150.

29 Ben Vedder, Heidegger's Philosophy of Religion (Pennsylvania: Duquesne University Press, 2006) 224.

30 Martin Heidegger, "Building Dwelling Thinking", art. cit., 150.

31 Ibid., 149-150.

32 Ibid., 150.

33 Ibid.

34 Ibid.

35 Bdk. ibid.

36 Gemma Corradi Fiumara, The Other Side of Language (London: Routledge, 1990) 1.

37 Martin Heidegger, Early Greek Thinking (New York: Harper and Row Publishers Inc., 1984) 60.

38 Bdk. Gemma Corradi Fiumara, op. cit., 21.

39 Martin Heidegger, On the Way to Language (New York: Harper \& Row, Publishers, 1971) 123.

40 Ibid., 122.

41 Martin Heidegger, Early Greek. Thinking, op. cit., 70

42 Bdk. Martin Heidegger, Being and Time, trans. John Macquarrie \& Edward Robinson (Oxford: Basil Blackwell, 1980) 56-58.

43 Michael Inwood, A Heidegger Dictionary (Oxford: Blackwell Publishers Ltd, 1999) 13.

44 Bdk. Martin Heidegger, Elucidations of Hölderlin Poetry, trans Keith Hoeller (New York: Humanity Books, 2000) 135-136.

45 Martin Heidegger, Being and Time, op. cit., 208.

46 Martin Heideggger, "Schöpferische Landschaft. Warum bleiben wir in der Provinz?" dikutip dari F. Budi Hardiman, op. cit., 136.

47 Martin Heidegger, Identity and Difference, transl. Joan Stambaugh (New York: Harper \& Row Publishers, 1969) 54-55.

48 Martin Heidegger, Being and Time, op. cit., 215.

49 Bdk. Charles B. Guignon, op.cit., 4.

50 Bdk. Ben Vedder, Heidegger's Phenomenology of Religion, op. cit., 244.

51 Bdk. Paus Paulus VI, Dei Verbum (1965) art. 2.

52 Bdk. Nico Syukur Dister, Teologi Sistematika (Yogyakarta: Kanisius, 2004) 67.

53 Bdk. Mircea Eliade (ed. in chief), The Encyclopedia of Religion Vol. 6 (New York: Macmillan Publishing Company, 1987) 173-176 dan B. Lewis et al. (eds.), The Encyclopadia of Islam Vol. III (London: Luzac \& Co. 1979) 99-104. 